\title{
Immunopresence and functional activity of prostaglandin-endoperoxide synthases and nitric oxide synthases in bovine corpora lutea during diestrus
}

\author{
M. Zerani, G. Catone, G. Betti, F. Parillo \\ Scuola di Scienze Mediche Veterinarie, Università di Camerino, Matelica, Italy \\ [Received 20 November 2012; Accepted 17 December 2012]
}

\begin{abstract}
The aim of this study was to evaluate the occurrence and the activity of prostaglandin-endoperoxide synthase 1 (PTGS1), PTGS2, and endothelial, neuronal, and inducible nitric oxide synthase (e-, n-, and iNOS) in early, mid, late, and regressive corpora lutea (CL) of bovines during diestrus. PTGS1 immunoreactivity was localised mainly in the cytoplasm of small luteal cells, whereas PTGS2 was detected in the cytoplasm of large luteal cells during early, mid, and late stages. The immunoexpression of all NOS isoforms was observed in the nuclei of luteal cells in the CL stages examined. PTGS1 enzyme activity was higher in late $C L$ and lower in regressive ones; PTGS2 increased from early to late $C L$ and lowered in regressive ones. Constitutive NOS enzymatic activity (eNOS plus nNOS) was higher in late CL and lower in regressive ones; iNOS was lower in regressive CL. These results support the idea that PTGSs and NOSs regulate the bovine CL life span mainly during the transition from the luteotrophic to the luteolytic phase. (Folia Morphol 2013; 72, 1: 36-40)
\end{abstract}

Key words: cattle, oestrous cycle, ovary, reproduction

\section{INTRODUCTION}

The corpora lutea $(\mathrm{CL})$ are transient ovarian organs that play a pivotal role for the establishment and maintenance of pregnancy by secreting progesterone [5]. Bovine CL contains cells with different anatomical features and biological functions, in particular, it contains steroidogenic cells, called large and small luteal cells, originating from follicle granulosa and theca cells, respectively $[1,2]$. In the cyclic female, the life span of CL is regulated by complex interactions between luteotrophic and luteolytic mediators [2]. Prostaglandins (PGs) play a key role in regulating the function and life span of CL. In fact, PGF2 $\alpha$ has been identified as the main luteolysing factor of uter- ine origin and PGE2 as luteotrophic factor [15]. In many species, the $C L$ themselves synthesize PGF2 $\alpha$ and PGE2 $[6,17]$. The critical step in PG biosynthesis is the enzymatic conversion of arachidonic acid into PGH2 by prostaglandin-endoperoxide synthase 1 (PTGS1) or PTGS2 [19]. PGH2, in turn, is converted into four structurally active PGs (PGE2, PGF2 $\alpha, P G D 2$, and PGI2) via specific PG synthases [14].

Nitric oxide (NO) is an intracellular messenger that is present in male and female reproductive organs of various mammalian species [4, 8, 9, 18, 19]. $\mathrm{NO}$ is synthesized from its precursor L-arginine by the action of NO synthase (NOS), which exists in three isoforms: calcium/calmodulin-dependent 
constitutive isoforms (endothelial, eNOS, and neuronal, nNOS), and calcium/calmodulin-independent inducible isoform (iNOS) [8].

The aim of the present study was to evaluate the cellular localisation and enzymatic activity of PTGS1, PTGS2, cNOS, and iNOS in early, mid, late, and regressive $\mathrm{CL}$ of bovine during diestrus.

\section{MATERIALS AND METHODS}

\section{Animals and tissue processing}

Uteri were collected along with the ovaries from cyclic cows at a local abattoir. CLs were separated by blunt dissection from the surrounding ovarian tissues and classified into four groups, covering the entire cycle length, as described previously [1, 3]: early (Days 4-6), mid (8-12), late (14-16), and regressive (19-21). CLs were cut in half longitudinally for the following immunohistochemical investigation and enzymatic activity assays.

\section{Immunohistochemistry of NOSs and PTGSs}

Tissue specimens were immediately processed for immunohistochemical investigation according to procedures previously described [11]. The slides were incubated with the following primary polyclonal antibodies (Abcam, Cambridge): rabbit anti-nNOS (1:250), rabbit anti-eNOS (1:10), rabbit anti-iNOS $(1: 200)$, rabbit anti-PTGS1 (1:50), and goat polyclonal anti-PTGS2 $(1: 50)$. Then they were incubated with biotin goat anti-rabbit secondary antibody for NOS isoforms and PTGS1 (Santa Cruz Biotechnology, CA) and biotin rabbit anti-goat secondary antibody for PTGS2 (Zymed Laboratories, CA). Finally, the slides were exposed to avidin-biotin complex ( $A B C$ kit, Vector Laboratories), and the peroxidase activity sites were visualised using a DAB kit (Vector Laboratories) as chromogen and, in some cases, were counterstained with Mayer's haematoxylin. Tissue sections in which the primary antibody was omitted or substituted by rabbit or goat IgG were used as negative controls of nonspecific staining (data not shown).

\section{PTGS and NOS enzyme activity}

PTGS1 and PTGS2 activities were determined by measuring the disappearance of the radiolabeled substrate $\left[{ }^{3} \mathrm{H}\right] \mathrm{AA}$ using a method reported elsewhere $[16,20]$. The PTGS1 activity was determined by calculating the rate of loss of $\left[{ }^{3} \mathrm{H}\right] \mathrm{AA}$ (Sigma-Aldrich, St Louis, MO, USA) incubated with selective PTGS2 inhibitor (NS-398, Calbiochem, San
Diego, CA, USA). The PTGS2 activity of each corresponding sample was determined by calculating the rate of loss of $\left[{ }^{3} \mathrm{H}\right] \mathrm{AA}$ incubated without selective PTGS2 inhibitor, and subtracting from this value that of PTGS1.

The activities of cNOS and iNOS were determined by monitoring the conversion of $\left[{ }^{3} \mathrm{H}\right] \mathrm{L}$-arginine to $\left.{ }^{3} \mathrm{H}\right] \mathrm{L}$-citrulline with a modified method previously described [11]. The cNOS activity (eNOS plus nNOS) was determined by calculating the $\left[{ }^{3} \mathrm{H}\right] \mathrm{L}$-citrulline synthesis rate in incubation buffer with iNOS inhibitor $1400 \mathrm{~W}$ (Calbiochem). The iNOS activity was determined by calculating the $\left[{ }^{3} \mathrm{H}\right] \mathrm{L}$-citrulline synthesis rate in incubation buffer without $1400 \mathrm{~W}$, and subtracting from this value that of cNOS.

\section{Statistical analysis}

All data were examined by Levene's test and one-way ANOVA followed by Student-Newman-Keuls $t$-test. Differences were considered significant at $p<0.01$.

\section{RESULTS AND DISCUSSION}

Various authors classify the bovine oestrous cycle into three different luteal periods on the basis of plasma progesterone levels [7]: growth (Days 4 to 7), static (8 to 16), and regression (17 to 21 ). Accordingly to other authors [1], we divided the oestrous cycle into four phases; in particular, the above reported static phase was subdivided into mid and late.

The immunopresence of PTGS1 was weakly evidenced in the cytoplasm of large luteal cells and strongly in small ones during the early, mid, and late stages (Fig. 1A); the cytoplasm of all luteal cells was weakly stained in the regressive $C L$ (Fig. 1B). PTGS2 was strongly detected in the cytoplasm of large luteal cells and weakly in small ones during early, mid, and late stages (Fig. 1C); all luteal cells were immunonegative in regressive $\mathrm{CL}$ (Fig. 1D). The differences in the PTGS1 and PTGS2 expression in small and large luteal cells, respectively, suggest a different role for these two PTGSs in modulating CL lifespan, as previously indicated in buffalo $[4,10]$. In this context, Arosh et al. [2] evidenced a PTGS2 cellular localisation in large luteal cells, whereas these authors did not report any data on PTGS1 immunolocalisation in bovine CL. As regards enzymatic activity, PTGS1 was higher $(p<0.01)$ in late CL (Fig. 2), while PTGS2 increased $(p<0.01)$ from early to late $\mathrm{CL}$ (Fig. 2). In previous studies on buffalo $\mathrm{CL}$ 

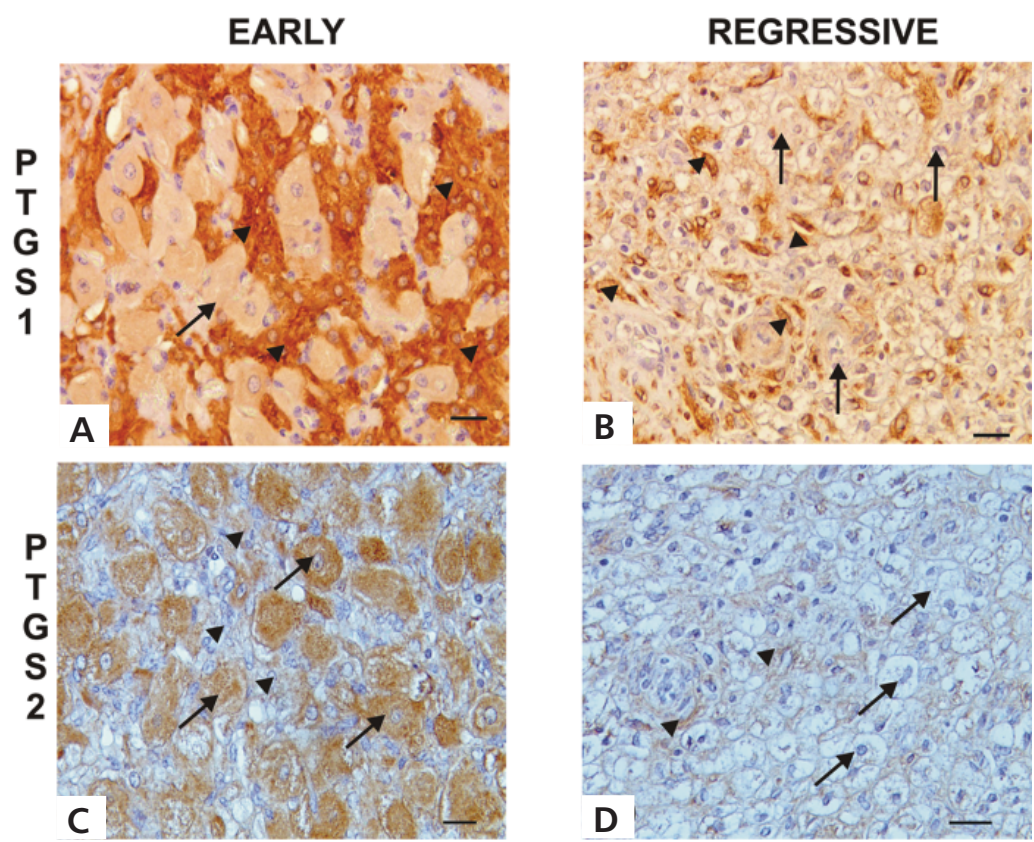

Figure 1. Prostaglandin-endoperoxide synthase 1 (PTGS1) immunostaining; A. Early corpora lutea (CL), cytoplasm of large luteal cells (arrows) and small luteal cells (arrowheads); B. Regressive CL, cytoplasm of luteal cells (arrows) and endothelial cells (arrowheads). PTGS2 immunostaining: C. Early CL, cytoplasm of large luteal cells (arrows) and small luteal cells (arrowheads); D. Regressive CL, luteal cells (arrows) and endothelial cells (arrowheads).

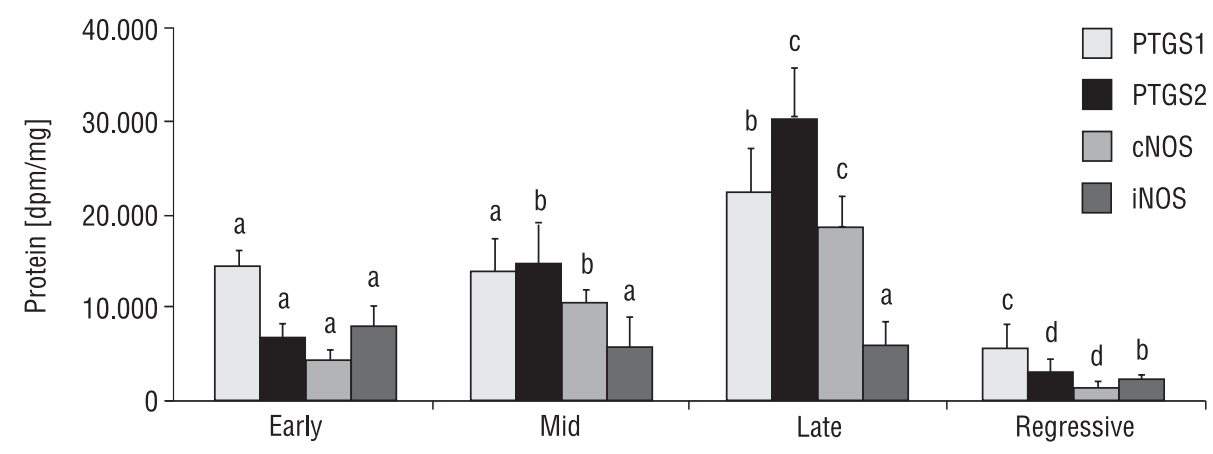

Figure 2. Enzyme activity of prostaglandin-endoperoxide synthase 1 (PTGS1), PTGS2, constitutive nitric oxide synthase (cNOS), and inducible NOS (iNOS) by early, mid, late, and regressive bovine corpora lutea. Values are shown as means \pm standard deviation of six replicates. Within each enzyme, different letters $(a, b, c, d)$ above the bars indicate significantly different values versus same luteal stage $(p<0.01)$.

$[10,11]$, it was shown that PTGS1 enzymatic activity was higher in late stage and lower in regressive CL, while PTGS2 increased from early to late CL and, differently from the present data, became higher in regressive $\mathrm{CL}$. It is interesting to note that regressive $\mathrm{CL}$ is accompanied by general decline $(p<0.01)$ of PTGS and NOS enzymatic activities (Fig. 2).

Immunosignals for nNOS were strongly observed in the nuclei of all luteal cells during all stages (Figs. 3A, B). Endothelial NOS reactive sites were strongly localized in the nuclei of luteal cells, whereas in the cytoplasm they were detected weakly in large cells and moderately in small ones during early, mid, and late stages (Fig. 3C); during the regressive stage eNOS was strongly detected in the nuclei of luteal cells (Fig. 3D). Inducible NOS immunoreactivity was weakly localised in the nuclei of luteal cells, weakly in the cytoplasm of large luteal cells, and moderately in the cytoplasm of small ones during early, mid, and late stages (Fig. 3E); conversely, during the regressive stage, it was strongly evidenced in the nuclei of all luteal cells and weakly in their cyto- 

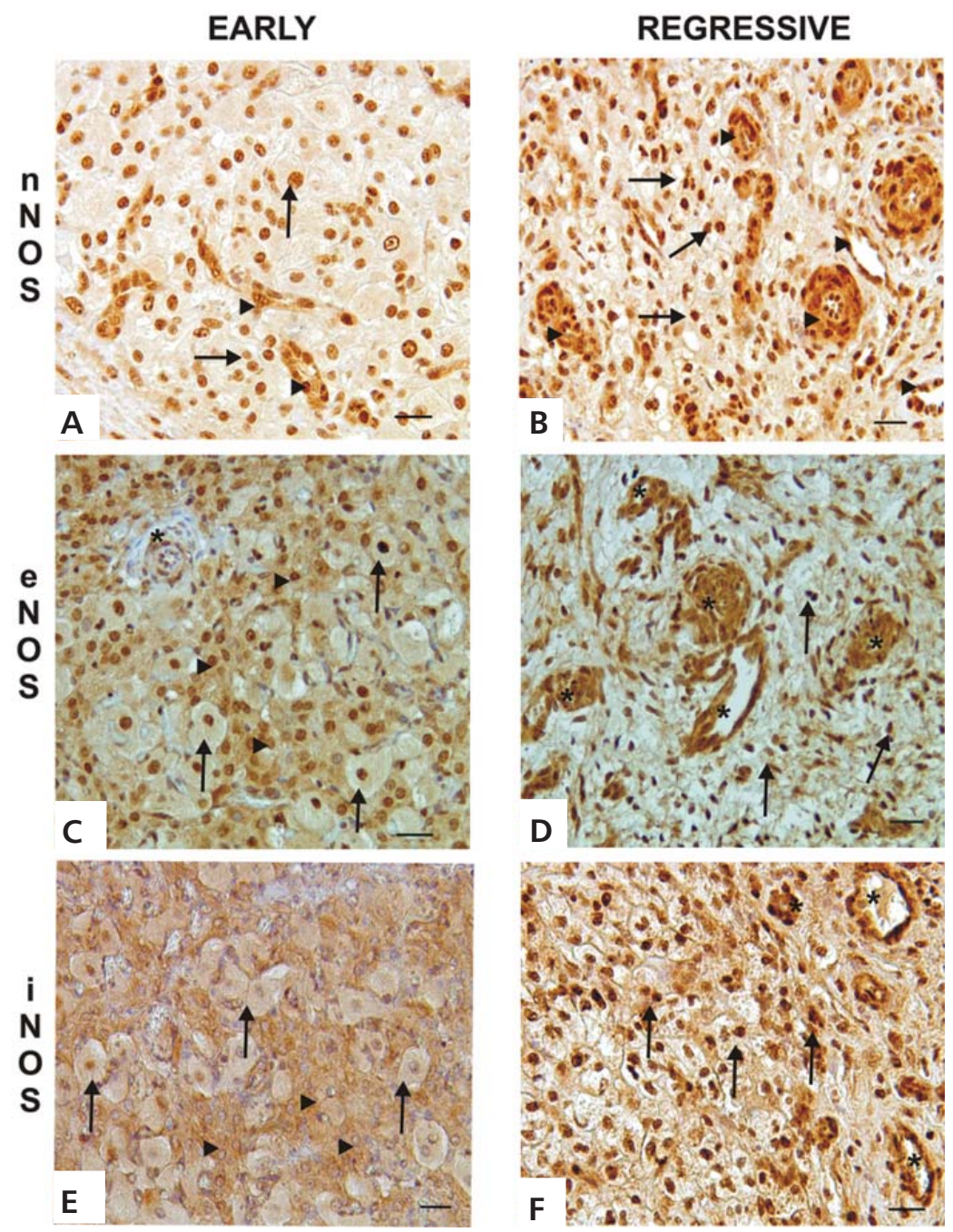

Figure 3. Neuronal nitric oxide synthase (nNOS) immunostaining; A. Early corpora lutea (CL), nuclei of luteal cells (arrows); B. Regressive $\mathrm{CL}$, nuclei of luteal cells (arrows); photos A and B, blood vessels wall (arrowheads). Endothelial NOS (eNOS) immunostaining; C. Early CL, cytoplasm of large luteal cells (arrows) and small luteal cells (arrowheads); D. Regressive CL, nuclei of luteal cells (arrows), in photos C and D, blood vessel wall (asterisks). Inducible NOS (iNOS) immunostaining; E. Early CL, cytoplasm of large luteal cells (arrows) and small luteal cells (arrowheads); F. Regressive CL, cytoplasm of luteal cells (arrows), blood vessel wall (asterisks).

plasm (Fig. 3F). Skarzynski et al. [13] reported that in bovine, eNOS and iNOS immunoreactivity increased from early to late stage of the oestrous cycle and then decreased in regressive $\mathrm{CL}$, whereas Rosiansky-Sultan et al. [12] indicated that eNOS protein expression was higher in the early and mid-luteal phase than in the late and regressed ones during the oestrous cycle in the cow. Constitutive NOS enzymatic activity increased $(p<0.01)$ from early to late $\mathrm{CL}$ (Fig. 2), whereas iNOS activity did not change from early to late stage CL (Fig. 2). In buffalo, differently from the present data, CNOS showed its higher activity levels also in mid CL, and iNOS was higher in late $\mathrm{CL}$ and lower in early ones [11].

\section{CONCLUSIONS}

In conclusion, these results shed new light on the mechanism regulating bovine reproduction, supporting the hypothesis that both PTGS and NOS enzymes are involved in the life span regulation of $\mathrm{CL}$, in particular they seem to play a role during the transition from the luteotrophic to the luteolytic phase.

\section{ACKNOWLEDGEMENTS}

This work was supported by generous donation from the PFZM Kitchenbrown Trust (Matelica, Italy). The authors gratefully acknowledge the revision of the English text by Sheila Beatty. 


\section{REFERENCES}

1. Arosh JA, Parent J, Chapdelaine P, Sirois J, Fortier MA (2002) Expression of cyclooxygenases 1 and 2 and prostaglandin $E$ synthase in bovine endometrial tissue during the estrous cycle. Biol Reprod, 67: 161-169.

2. Arosh JA, Banu SK, Chapdelaine P, Madore E, Sirois J, Fortier MA (2004) Prostaglandin biosynthesis, transport and signaling in corpus luteum: a basis for autoregulation of luteal function. Endocrinology, 145: 2551-2560.

3. Catone G, Zerani M, Russo M, Mancuso R, Parillo F (2009) Presence and enzymatic activity of COX1, COX2 and NOS in bovine corpora lutea during luteal phase. Reprod Dom Anim, 44 (suppl. 3): 99.

4. Catone G, Zerani M, Castellucci B, Ciccarelli M, Currenti M, Gobbetti A, Parillo F (2011). Gonadotropin-releasing hormone $(\mathrm{GnRH})$ receptor expression and in vitro $\mathrm{GnRH}$ effects in early-, mid- and late-corpora lutea of mediterranean buffalo (Bubalus bubalis). Reprod Dom Anim, 46 (suppl. 3): 93-94.

5. Davis JS, Rueda BR (2002) The corpus luteum: an ovarian structure with maternal instincts and suicidal tendencies. Front Biosci, 7: 1949-1978.

6. Guelfi G, Zerani M, Brecchia G, Parillo F, Dall'Aglio C, Maranesi M, Boiti C (2011) Direct actions of ACTH on ovarian function of pseudopregnant rabbits. Mol Cell Endocrinol, 339: 63-71.

7. Herzog K, Brockhan-Lüdemann M, Kaske M, Beindorff N, Paul V, Niemann H, Bollwein H (2010) Luteal blood flow is a more appropriate indicator for luteal function during the bovine estrous cycle than luteal size. Theriogenology, 73: 691-697.

8. McCann SM, Mastronardi C, De Laurentiis A, Rettori V (2005) The nitric oxide theory of aging revisited. Ann NY Acad Sci, 1057: 64-84.

9. Parillo F, Catone G, Boiti C, Zerani M (2011a) Immunopresence and enzymatic activity of nitric oxide synthases, cyclooxygenases and PGE2-9-ketoreductase and in vitro production of PGF2alpha, PGE2 and testosterone in the testis of adult and prepubertal alpaca (Lama pacos). Gen Comp Endocrinol, 171: 381-388.

10. Parillo F, Catone G, Castellucci B, Vullo C, Betti G, Mari S, Zerani M (2011b) Immunopresence and enzymatic activity of nitric oxide syntases, cyclooxygenases, and PGE2-9-ketoreductase and in vitro production of progesterone, PGF2alpha, and PGE2 in mediterranean buffalo (Bubalus bubalis) corpora lutea during diestrus. Reprod Dom Anim, 46 (suppl. 3): 138.

11. Parillo F, Catone G, Maranesi M, Gobbetti A, Gasparrini B, Russo M, Boiti C, Zerani M (2012) Immunolocalization, gene expression, and enzymatic activity of cyclooxygenases, prostaglandin E2-9-Ketoreductase, and nitric oxide synthases in Mediterranean buffalo (Bubalus bubalis) corpora lutea during diestrus. Micr Res Techn, doi: 10.1002/jemt.22116.

12. Rosiansky-Sultan M, Klipper E, Spanel-Borowski K, Meidan R (2006) Inverse relationship between nitric oxide synthases and endothelin-1 synthesis in bovine corpus luteum: interactions at the level of luteal endothelial cell. Endocrinology, 147: 5228-5235 .

13. Skarzynski DJ, Jaroszewski JJ, Bah MM, Deptula KM, Barszczewska B, Gawronska B, Hansel W (2003) Administration of a nitric oxide synthase inhibitor counteracts prostaglandin F2-induced luteolysis in cattle. Biol Reprod, 68: 1674-1681.

14. Watanabe K (2002) Prostaglandin F synthase. Prostaglandins Other Lipid Mediat, 68-69: 401-407.

15. Wiltbank MC, Ottobre JS (2003) Regulation of intraluteal production of prostaglandins. Reprod Biol Endocrinol, 1: 91.

16. Zerani M, Dall'Aglio, C, Maranesi M, Gobbetti A, Brecchia G, Mercati F, Boiti C (2007) Intraluteal regulation of prostaglandin F2alpha-induced prostaglandin biosynthesis in pseudopregnant rabbits. Reproduction, 133: 1005-1016.

17. Zerani M, Parillo F, Brecchia G, Guelfi G, Dall'Aglio C, Lilli L, Maranesi M, Gobbetti A, Boiti C (2010) Expression of type I GNRH receptor and in vivo and in vitro GNRH-I effects in corpora lutea of pseudopregnant rabbits. J Endocrinol, 207: 289-300.

18. Zerani M, Catone G, Quassinti L, Maccari E, Bramucci M, Gobbetti A, Maranesi M, Boiti C, Parillo F (2011) In vitro effects of $\mathrm{GnRH}$ on Leydig cells of adult alpaca (Lama pacos) testis: GnRH receptor immunolocalization, testosterone and prostaglandin synthesis, and cyclooxygenase activities. Dom Anim Endocrinol, 40: 51-59.

19. Zerani M, Catone G, Maranesi M, Gobbetti A, Boiti C, Parillo F (2012) Gonadotropin-releasing hormone 1 directly affects corpora lutea lifespan in mediterranean buffalo (Bubalus bubalis) during diestrus: presence and in vitro effects on enzymatic and hormonal activities. Biol Reprod, 87: 1-8.

20. Zerani M, Maranesi M, Brecchia G, Gobbetti A, Boiti C, Parillo F (2013) Evidence for a luteotropic role of peroxisome proliferator-activated receptor gamma: expression and in vitro effects on enzymatic and hormonal activities in corpora lutea of pseudopregnant rabbits. Biol Reprod, DOI: 10.1095/biolreprod.112.10.7383. 